Supplement of Atmos. Chem. Phys., 21, 6005-6022, 2021

https://doi.org/10.5194/acp-21-6005-2021-supplement

(C) Author(s) 2021. CC BY 4.0 License.

(c) (1)
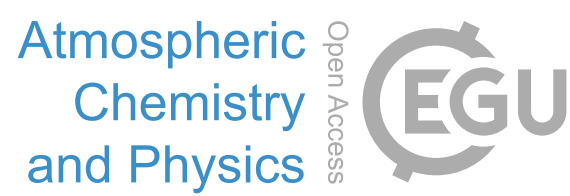

Supplement of

\title{
Volatile organic compound emissions from solvent- and water-borne coatings - compositional differences and tracer compound identifications
}

Chelsea E. Stockwell et al.

Correspondence to: Chelsea E. Stockwell (chelsea.stockwell@ noaa.gov) and Carsten Warneke (carsten.warneke@ noaa.gov)

The copyright of individual parts of the supplement might differ from the article licence. 


\section{S1. Detailed Description of GC Front End to PTR-ToF-MS}

During operation, ambient air or headspace samples are sampled by the GC at a flow rate of 20 sccm through a $1.58 \mathrm{~mm}$ PTFE sample line into a heated 10-port 2-way chromatography valve (VICI) in the "load" position, as shown in Figure S1. The sample is then directed through a water trap to remove excess water and a sample trap to pre-concentrate sample analytes as described in detail below. The flow rate $(20 \mathrm{sccm})$ is maintained by a mass flow controller (MFC2 in Fig. S1) and vacuum pump. After a userspecified volume has been collected (20-200 ml), the 10-port valve is switched to the "inject" position, and the sample and water traps are heated. Nitrogen $\left(\mathrm{N}_{2}\right)$ is used as a carrier gas to transport the VOCs to the head of the GC column (Agilent Technologies, $30 \mathrm{~m}, 0.25 \mathrm{~mm}$ ID, $1.4 \mu \mathrm{m}$ film thickness) because $\mathrm{N}_{2}$ does not significantly change the ion mobility in the PTR drift tube, unlike the lighter gases typically used in GCs (e.g., helium or hydrogen).

The water trap consists of $0.8 \mathrm{~mm}$ ID (1.58 mm OD) PTFE tubing inside a $15 \mathrm{~cm}$ length $(1.5 \mathrm{~cm}$ OD, $1 \mathrm{~cm} \mathrm{ID)} \mathrm{brass} \mathrm{annulus} \mathrm{that} \mathrm{has} \mathrm{a} 2 \mathrm{~mm}$ fin that extends from the bottom of the tube into a $10 \mathrm{~L}$ liquid nitrogen dewar. This fin provides the cooling to the surrounding trap. The water trap temperature is maintained at $-5^{\circ} \mathrm{C}$ during trapping using a $\sim 250 \mathrm{~W}$ heater constructed of insulated Nichrome resistance wire wrapped around an outer stainless steel tube (3.2 mm OD, $2.5 \mathrm{~mm}$ ID) that holds the PTFE. A 1/16" type-T thermocouple probe is mounted between the stainless steel and PTFE tubing to measure and control the cold and warm (trapping/releasing) temperatures. After the sample is injected, the water trap is heated to $50^{\circ} \mathrm{C}$ and nitrogen pushes water vapor out through a vent port in preparation for the next sample. This purge flow rate is $\sim 100 \mathrm{~mL} \mathrm{~min}^{-1}$ and controlled by a flow restrictor. There are some losses of the heavier ( $\sim \mathrm{C} 8$ and larger) VOCs within the water trap, but because the temperatures are controlled and consistent, these losses are accounted for during calibration.

The sample trap is a $17 \mathrm{~cm}$ piece of $0.32 \mathrm{~mm}$ ID passivated stainless steel guard column (Restek Corporation) suspended inside a piece of thin-walled hypodermic stainless steel tubing (1.59 mm OD, 1.43 mm ID). The gas fittings on either end are modified 1/32" chromatography fittings designed to fit inside small brass "end heaters". The purpose of these end heaters is to prevent VOCs from being trapped outside of the intended cold zone. The sample trap and stainless steel hypodermic tubing are electrically isolated from the rest of the assembly by using PTFE transfer lines and vespel (VICI) ferrules. The sample trap is suspended inside a piece of copper in the shape of a thin-annulus similar to the brass one described above. A $5 \mathrm{~mm}$ thick copper fin (15 cm long) is connected to the bottom of the copper annulus and extends into the same liquid nitrogen to provide cooling. The sample and water traps are mounted above the dewar and insulated using tightly fitting polystyrene foam insulation. During the sample collection period, the sample trap is maintained at a user-defined set point (typically $-100^{\circ} \mathrm{C}$ ) by running an $\mathrm{AC}$ current from a 120:3 V 
transformer directly through the thin-walled hypodermic tubing. A type $\mathrm{T}$ thermocouple is encapsulated between the trap itself and the hypodermic tubing to measure and control the temperature.

During sample injection, the sample trap is heated to $110^{\circ} \mathrm{C}$ and forward flushed with $\mathrm{N}_{2}$ carrier gas that transfers the trapped analytes to the 10-port valve and then on to the GC column through a heated transfer line $\left(40^{\circ} \mathrm{C}\right)$ at $8 \mathrm{sccm}$. At the same time, the water trap is flushed at $40^{\circ} \mathrm{C}$ with $\mathrm{N}_{2}$ carrier gas at a flow of $100 \mathrm{~mL} \mathrm{~min}{ }^{-1}$. The GC oven starts at $40{ }^{\circ} \mathrm{C}$ and held for 2 minutes. The temperature is then ramped at $10{ }^{\circ} \mathrm{C} \min ^{-1}$ to $150{ }^{\circ} \mathrm{C}$. It is held at the final temperature for 30 seconds before being cooled again in preparation for the next sample. The four-port valve is shown directing column effluent to the mass spectrometer, while ambient air is vented. Depending on the application, 1-5 minute samples can be collected and chromatogram lengths of 10-20 minutes can be chosen such that the total run time is between 15 and 30 minutes. LabVIEW (National Instruments) software controls the sequence of events, hot and cold trap temperatures, transfer line heaters valve switching, sample flow and carrier gas flow. Calibration standards containing components with carbon numbers ranging from acetone $(\mathrm{C} 3)$ to monoterpenes $(\mathrm{C} 10)$ were tested to ensure that compounds were trapped and released through the water trap, sample trap and sampling lines and could be quantitatively detected by the PTR-ToF-MS. Both polar and non-polar compounds were tested including acetone, isoprene, BTEX compounds, indene, crotonaldehyde, 2,3, methyl buten-2ol, and methyl ethyl ketone. To analyze larger (and less volatile) molecules such as C12C15 alkenes, sesquiterpenes, tri-isopropyl benzene or Texanol (C12), the trapping system would have required modifications. Among these are higher transfer line temperatures, higher water trap temperature, longer sampling times, higher GC oven temperature and possibly a different analytical column. Since the initial characterization included identification and quantification of the vast majority of VOCs observed in ambient air with a total cycle time of approximately 15 minutes, the design criteria were met. Further efforts to analyze heavier or lighter compounds (e.g. acetylene) were not pursued. 


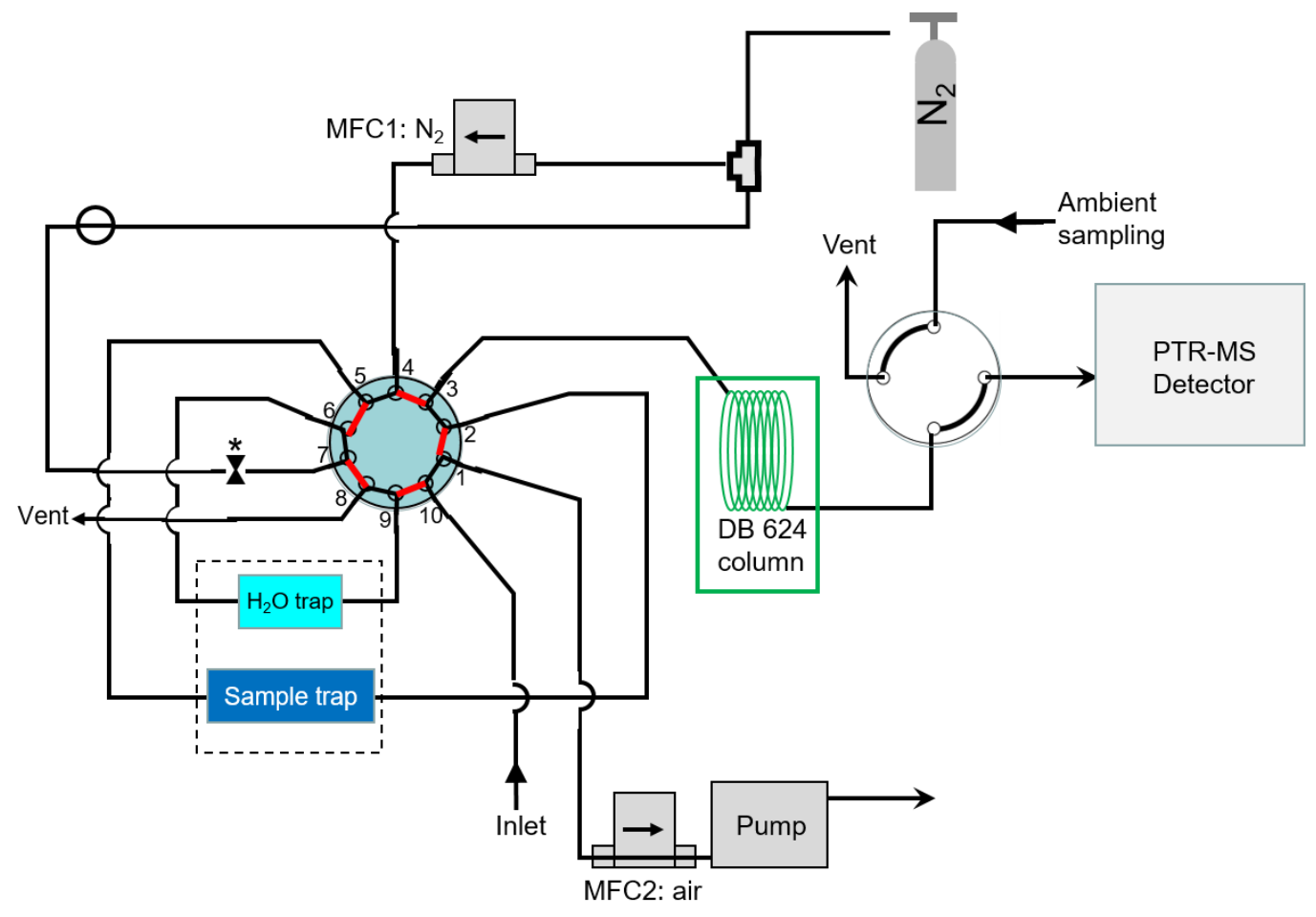

Figure S1. The GC front-end instrument diagram showing the load (red) and inject (black) positions of the 10-port 2-way chromatography valve. 